\title{
Symptom burden in individuals with cerebral palsy
}

\author{
Adam T. Hirsh, PhD; ${ }^{1 *}$ Juan C. Gallegos, BA; ${ }^{1}$ Kevin J. Gertz, BA; ${ }^{1}$ Joyce M. Engel, PhD; ${ }^{2}$ Mark P. Jensen, PhD ${ }^{1}$ \\ ${ }^{1}$ Department of Rehabilitation Medicine, University of Washington School of Medicine, Seattle, WA; ${ }^{2}$ Department of \\ Occupational Science and Technology, University of Wisconsin-Milwaukee, Milwaukee, WI
}

\begin{abstract}
The current study sought to (1) determine the relative frequency and severity of eight symptoms in adults with cerebral palsy (CP), (2) examine the perceived course of these eight symptoms over time, and (3) determine the associations between the severity of these symptoms and psychosocial functioning. Eighty-three adults with CP completed a measure assessing the frequency, severity, and perceived course of eight symptoms (pain, weakness, fatigue, imbalance, numbness, memory loss, vision loss, and shortness of breath). Respondents also completed measures of community integration and psychological functioning. The results indicated that pain, fatigue, imbalance, and weakness were the most common and severe symptoms reported. All symptoms were reported to have either stayed the same or worsened, rather than resolved, over time. The symptoms were more closely related to social integration than to home integration, productive activity, or psychological functioning. Memory loss was a unique predictor of social integration in the multivariate context. This study highlighted several common and problematic symptoms experienced by adults with CP. Additional research is needed to identify the most effective treatments for those symptoms that affect community integration and psychological functioning as a way to improve the quality of life of individuals with CP.
\end{abstract}

Key words: cerebral palsy, community integration, fatigue, imbalance, pain, psychological functioning, quality of life, rehabilitation, signs and symptoms, weakness.

\section{INTRODUCTION}

Cerebral palsy (CP) is a neurodevelopmental disorder of movement and posture [1]. The onset of CP occurs very early in life, and although it is described as a nonpro- gressive disorder, research over the past several years has highlighted a number of health conditions and functional declines experienced by individuals with CP as they age [2-5]. This is an important line of research since the vast majority of individuals with this condition survive until at least early adulthood [6-7]. In fact, the number of adults living with CP in the United States is estimated to be approximately 400,000 [4]. There has also been an increasing trend over time for adults with CP to be integrated into the community, as opposed to being housed in long-term care facilities [8]. Taken together, these facts indicate the need for research focused on the experience of adults living with $\mathrm{CP}$, as well as the relationship between the associated symptoms and both community integration and psychological functioning.

Neuromotor abnormalities comprise the characteristic physical features of CP. More recently, the experience of pain in individuals with $\mathrm{CP}$ has been recognized. In one of the first studies to examine pain in this population, Turk et al. found that 84 percent of their sample of women experienced chronic pain in at least one body

\footnotetext{
Abbreviations: $\mathrm{CIQ}=$ Community Integration Questionnaire, $\mathrm{CP}=$ cerebral palsy, MHS = Mental Health Scale (of the SF-36), MMSE $=$ Modified Mini-Mental Status Examination, SCI $=$ spinal cord injury, SD = standard deviation, SF-36 = Medical Outcomes Study 36-Item Short Form Health Survey.

* Address all correspondence to Adam T. Hirsh, PhD; Department of Psychology, Indiana University-Purdue University Indianapolis, 402 N Blackford St, LD 124, Indianapolis, IN 46202; 317-274-6942; fax: 317-2746756. Email: athirsh@iupui.edu
}

DOI:10.1682/JRRD.2010.03.0024 
location [9]. Research from our group has also found high rates of chronic pain in this population. For example, using different samples of adults with CP, both Schwartz et al. [10] and Engel et al. [11] found that 67 percent of participants reported pain of at least 3 months duration, with a substantial number of these individuals having pain on a daily basis. In Europe, higher rates of chronic pain have been found in patients with CP than in the general population [12].

Fatigue is also common in adults with $\mathrm{CP}$ and is associated with increased bodily pain, reduced functioning, and poorer overall quality of life [13-14]. A related symptom, weakness, is also prevalent in this patient population and may be caused by any of the following: decreased central input into the muscle [15], changes in muscle elasticity [16], aberrations in the reciprocal inhibition pathways in agonist-antagonist muscle pairs [17], and heightened stretch responses or spasticity [18]. Weakness in individuals with CP can also be caused and/ or exacerbated by decreased physical activity [19].

Respiratory dysfunction as a result of scoliosis is welldocumented in the general, non-CP literature [20]. Since scoliosis is common in individuals with $\mathrm{CP}$, occurring in up to 64 percent of institutionalized adults in one study [21], dyspnea may be a particularly common and debilitating symptom experienced by adults with CP. Moreover, the associated nocturnal pulmonary dysfunction may cause sleep disturbance and, thus, contribute to daytime weakness and fatigue [22]. Dyspnea has been shown to be associated with motorized wheelchair use in individuals with spinal cord injury (SCI) [23-24]; however, we could not identify any research that has examined this in adults with $\mathrm{CP}$, despite the high rates of wheelchair use in this population [12-25]. Given these two factors (scoliosis prevalence and wheelchair use), individuals with CP would seem to be at increased risk for breathing difficulties [26].

Perceptual abnormalities associated with CP have also been noted. Visual impairments have been found to be present in 25 to 39 percent of patients [27], the likely causes of which include cataracts, optic atrophy, and retinitis. Moreover, these impairments may worsen over time [28].

The motor and perceptual disturbances of $\mathrm{CP}$ are often accompanied by impairments in cognitive functioning and learning difficulties [1,29]. Unfortunately, the empirical literature regarding cognitive functioning in adults with CP is relatively thin. Specifically, the extent to which these individuals experience memory problems has not been widely investigated. This is a conspicuous gap in the literature given that in the general population, memory decline in adulthood is common and is associated with decreased psychosocial functioning [30-33]. One recent study found memory impairments in 21 to 67 percent of participants with CP [34]; however, the study sample was composed of children, adolescents, and adults, which makes it difficult to determine the extent of these impairments among adults with CP.

Although adults with CP have been subject to increasing empirical attention in recent years, the $\mathrm{CP}$ literature continues to be focused primarily on children. A number of diverse symptoms of CP in adults have been highlighted in the literature; however, we continue to have an incomplete understanding of the experience of these individuals. Few studies have investigated the extent to which symptoms of CP change with time, that is, whether symptoms are perceived to have improved, worsened, or stayed the same. Furthermore, the extent to which symptoms are related to community integration and psychological functioning has not been subjected to much empirical scrutiny. Is fatigue severity related to performance of household activities? Is memory impairment associated with social engagement? Is pain severity associated with psychological functioning? Although it may seem intuitive that many symptoms of $\mathrm{CP}$ - particularly those that have been found to negatively affect quality of life in other patient groups-have important implications for patient functioning, research is needed to confirm these assumptions. Such research has important clinical implications, since it may help clinicians decide which symptoms to focus on for assessment and treatment.

The overall purpose of the current study was to further our understanding of the nature and impact of a number of symptoms commonly reported by adults with CP. The three specific aims were as follows: (1) examine the frequency and severity of pain, weakness, fatigue, imbalance, numbness, memory loss, vision loss, and shortness of breath in a sample of adults with CP; (2) examine participants' perceptions of whether these eight symptoms have improved, gotten worse, or stayed the same over time; and (3) calculate the associations among the eight symptoms and the associations between the severity of these symptoms and both psychological functioning and community integration. Many of the symptoms investigated in this study were included because previous research (reviewed previously in this section) indicated that they are relatively common among individuals with 
CP. Other symptoms (e.g., numbness), for which little or no prevalence data are available, were also included based on our clinical experience, which suggests these symptoms are experienced by a considerable number of patients with this condition.

We hypothesized that the frequency of pain in the current sample would be consistent with previous reports [10-11]. We also expected that the majority of respondents would report that their pain had stayed the same or gotten worse over time, because preliminary evidence indicates that CP-related pain is relatively refractory [12]. Hypotheses were not proposed regarding the specific frequency or perceived course of other symptoms reported by the sample, however, given the relative lack of previous research in these areas. Finally, we hypothesized that the severity ratings for each symptom would independently contribute to the concurrent prediction of community integration and psychological functioning in the sample.

\section{METHODS}

\section{Recruitment and Data Collection}

Two recruitment and data collection strategies were used for the current study: in-person interviews and mailed questionnaires. This reflects a procedural change by our research group over the course of the study; recruitment and data collection evolved from in-person to postal primarily because of the significant resource burden of the former. The same study questionnaire was used for in-person and postal procedures.

\section{In-Person Interviews}

Individuals who participated in previous interview studies performed by our group [10-11,35] were sent an approach letter that provided information about the current research study. The recruitment sources for the previous studies included medical and rehabilitation clinics at the University of Washington Medical Center and local residential and community-based treatment facilities for persons with developmental disabilities. Individuals who were interested in participating in the current study were instructed to either contact research personnel by telephone or return an enclosed postage-paid postcard indicating their interest. Participants who initiated telephone contact were read a recruitment script that informed them about the study. Research personnel also answered any questions and scheduled a time to conduct an interview either at the University of Washington or the individual's home. In addition, all individuals completed the Modified Mini-Mental Status Examination (MMSE) to assess their cognitive status [36]. Individuals were eligible to participate if they scored 17 or higher out of a possible score of 25 or if they scored 14 or higher and used a communication device. The MMSE was completed prior to the study questionnaire, and only basic demographic information was collected from individuals who did not meet the MMSE eligibility requirement. Interviews with eligible participants were approximately 60 to 90 minutes in length. All participants, including those who were ineligible because of low MMSE scores, were paid \$25. Participants were also provided parking validation or bus passes if they attended the interview at the University of Washington.

\section{Questionnaires Completed by Mail}

Participants were also permitted to complete the questionnaire on their own and send the completed questionnaire to research personnel. Descriptions of the study were posted on the departmental Web site, and flyers were posted in University of Washington Medical Center clinics for recruitment purposes. Individuals were instructed to contact research personnel if they were interested in participating. Interested individuals were sent a packet that contained an approach letter explaining the study in further detail, two copies of the study consent form, a basic contact information sheet, and the study questionnaire. Participants were instructed to read and complete one copy of the consent form and keep the other copy for their records. They were also instructed to complete the contact information sheet and questionnaire. Participants were permitted to obtain assistance from a significant other if fine motor difficulties prevented them from completing the materials on their own; in such instances, the significant other was instructed to answer the questions as indicated by the participant and not provide their own responses. A postage-paid envelope was provided for participants to return the completed materials. Research personnel reviewed the materials upon receipt and contacted participants who did not complete the materials or provided unclear responses. Participants who completed at least a portion of the questionnaire were paid $\$ 25$. The mailed version of the questionnaire included the same outcome measures as the version completed in person but did not include the MMSE because this measure cannot be appropriately administered by mail. 


\section{Participants}

A total of 206 prospective participants were contacted or had contact with research personnel regarding this study. The primary recruitment sources for this study (169 individuals, [82\%]) were previous interview studies conducted by our research group [10-11,35]. Participants were also recruited via flyers and descriptions on the departmental Web site. In addition, individuals also learned about the study through discussion with healthcare providers, study investigators, and previous research participants. Thirty-four individuals (16.5\%) learned about the study in this word-of-mouth manner. Furthermore, three individuals (1.5\%) who completed a pediatric survey study entitled "Survey of Chronic Pain and Its Effects on Youths with Disabilities" were contacted once they reached the age of 18 to see whether they were interested in participating in the current study.

Of the 206 prospective participants, 6 individuals (3\%) were deceased. Forty-one individuals (19.9\%) could not be reached by telephone or mail. Of the remaining 159 prospective participants, 35 individuals (22\%) declined to participate and 28 individuals (17.6\%) failed to return telephone calls, attend the interview session, or return a completed questionnaire via mail. The stated reasons for declining to participate were varied, with the modal response being lack of time and/or interest. One individual $(<1 \%)$ was nonverbal and unable to complete the survey in person. Sixty-one individuals attended an in-person interview session and consented to participate in the study. Of these 61 participants, 50 met the MMSE eligibility criteria described previously. Fifteen participants used an augmentative communication device during the interview. Thirty-four participants completed surveys on their own and returned these via mail. One returned survey was not sufficiently complete (i.e., it contained a large number of missing items for the primary variables of interest), and follow-up attempts to collect data for the missing items were not successful; therefore, this survey was not included in the analyses for this study. In total, the final convenience sample for the current study consisted of 83 participants. This represents a response rate of 52.2 percent (excluding individuals who were deceased or not reachable by telephone or mail).

\section{Measures}

\section{Demographic and Clinical Characteristics}

The survey assessed basic demographic characteristics (age, sex, education level, employment status, race/ ethnicity, marital status) and descriptive information about participants' CP condition (CP type, areas of the body affected, use of ambulatory devices). Participants were asked to rate the current presence and severity of each of the following eight symptoms: pain, weakness, fatigue, imbalance, numbness, memory loss, vision loss, and shortness of breath. Ratings were provided on a 0 (none) to 10 (very severe) scale. Survey respondents were also asked to indicate the short-term and long-term course of those symptoms (i.e., whether each symptom had become worse, become better, or stayed the same both since its onset and over the past 6 months). The eight symptoms were chosen based on (1) our clinical experience that at least some individuals with CP reportedly experience these symptoms and (2) previous research indicating that these symptoms are indeed reported by individuals with CP.

\section{Community Integration}

Community integration was assessed with the 13item Community Integration Questionnaire (CIQ) [37]. The CIQ is a measure of the lack of disability (ability to perform normal role functions in and outside the home) in three domains of functioning: home activity (e.g., meal preparation, housework), social activity (e.g., leisure activities with others), and productive activity (e.g., employment status). These domains correspond to the CIQ subscales of Home Integration, Social Integration, and Productive Activities, respectively. Previous research supports the reliability and validity of the CIQ scales [37-38].

\section{Psychological Functioning}

Psychological functioning was assessed with the 5-item Mental Health Scale (MHS) of the Medical Outcomes Study 36-Item Short-Form Health Survey (SF-36) [39]. Scores on the MHS range from 0 to 100 , with higher scores indicating better psychological functioning. This measure is widely used and has demonstrated strong psychometric properties [39]. 


\section{Statistical Analyses}

The survey response rate and respondents' demographic and CP clinical information were examined for descriptive purposes. The frequency of each symptom and average severity ratings were then computed for each of the eight symptoms. Severity ratings were calculated both for the entire sample and specifically for those individuals who endorsed the particular symptom (i.e., those who rated the severity as " 1 " or greater). Next, the frequencies of each course type (worse, same, better) associated with the eight symptoms were computed. Different frequency calculations were conducted for two time periods: since symptom onset and during the past 6 months. These analyses allowed for determination of participants' perceptions of symptom change over time.

Pearson correlation coefficients were then computed between the symptom severity ratings to determine the extent to which these ratings overlapped. High correlation coefficients $(r>0.50)$ among the ratings would suggest a possible higher order factor-such as depression or somatization - that might have influenced participants' symptom reporting. Correlation analyses were also conducted to examine the zero-order associations among the eight symptoms and four criterion measures of functioning (CIQ Home Integration, CIQ Social Integration, CIQ Productive Activities, and SF-36 MHS). Due to the large number of correlation analyses and consequent increased risk of type I error, a Bonferroni adjusted alpha $(0.05 / 32$ tests $=0.0016)$ was used to determine statistical significance.

Finally, four multiple regression analyses were conducted, with one of the functioning measures serving as the criterion variable in each model. Participant age and sex were controlled for in the regressions because the frequency of symptoms is likely to increase with age and because age and sex have been found to be associated with both community integration and psychological functioning in other disability groups [40-43]. After controlling for age and sex in step 1 of the regression models, we simultaneously entered severity ratings for the eight symptoms in step 2 to determine their unique contributions to the prediction of functioning.

\section{RESULTS}

\section{Participant Characteristics}

The final sample $(n=83)$ was 55 percent female, with an average age of 40.34 years ( \pm standard deviation
[SD] 13.55 , range $=18-74$ years). The vast majority of participants self-reported as white (88\%). Sixty-five percent had never been married, twenty-six percent were married or living with a partner, and the remainder were separated or divorced. More than half of the participants reported some level of education beyond high school (59\%), and only 13 percent did not graduate high school or attain a General Educational Development diploma. In terms of employment, 43 percent of participants were working full- or part-time. Fifty-nine percent of participants required a wheelchair (manual and/or electric) for mobility. Twenty-nine percent of the sample walked with canes, crutches, and/or a walker, and eight percent used a scooter. Twenty-five percent did not require any assistance with ambulation.

Almost half of the participants had spastic CP (47\%), with the remainder having mixed (29\%), athetoid (16\%), ataxic (1\%), or hypotonic (1\%) CP; 6 percent did not report the type of CP. The majority of participants had tetraplegia (59\%), whereas 21 percent had diplegia, 16 percent had hemiplegia, and 2 percent had monoplegia. One participant did not respond to the item concerning the area of the body affected by CP.

\section{Frequency and Course of Symptoms}

Pain was the most common symptom reported by study participants (72\%), followed by fatigue (64\%), imbalance (55\%), and weakness (52\%) (Table 1). Numbness (33\%), shortness of breath (29\%), memory loss (23\%), and vision loss (19\%) were reported less frequently. Pain was also the most severe symptom, with 23 percent of participants reporting pain levels of 7 or greater on the 0 to 10 scale (mean \pm SD severity rating for the entire sample was $3.65 \pm 3.16$ ). Twenty percent of participants reported severe levels ( 7 or greater) of fatigue (sample mean $\pm \mathrm{SD}=3.28 \pm 3.13$ ), and nineteen percent reported severe levels of imbalance (sample mean $\pm \mathrm{SD}=3.18 \pm 3.35$ ). Fewer participants reported severe levels of weakness, numbness, shortness of breath, vision loss, and memory loss (Table 1).

All eight symptoms were more often reported to have stayed the same (range $=33 \%-52 \%$ ) or gotten worse (range $=28 \%-53 \%$ ) since their onset, as opposed to have gotten better (range $=13 \%-29 \%$ ). In terms of how symptoms have or have not changed over the past 6 months, participants more often reported that their symptoms have stayed about the same (range $=45 \%-74 \%$ ) over this time period. When change did occur during the past 6 months, 
JRRD, Volume 47, Number 9, 2010

Table 1.

Frequency and course of symptoms ( $N=83$ for entire sample).

\begin{tabular}{|c|c|c|c|c|c|c|c|c|c|}
\hline \multirow[t]{2}{*}{ Symptom* } & \multirow{2}{*}{$\begin{array}{l}\text { Frequency of } \\
\text { Occurrence } \\
\quad(\% \geq 1)\end{array}$} & \multirow{2}{*}{$\begin{array}{c}\text { Frequency of } \\
\text { Severe Symptom } \\
(\% \geq 7)\end{array}$} & \multirow{2}{*}{$\begin{array}{c}\text { Average } \\
\text { Severity }^{\dagger} \\
(\text { mean } \pm \text { SD) }\end{array}$} & \multicolumn{3}{|c|}{$\begin{array}{c}\text { Course Since Onset }^{\dagger} \\
(\%)\end{array}$} & \multicolumn{3}{|c|}{$\begin{array}{c}\text { Course Last } 6 \text { Months }{ }^{\dagger} \\
(\%)\end{array}$} \\
\hline & & & & Worse & Same & Better & Worse & Same & Better \\
\hline Weakness & 52 & 11 & $4.53 \pm 2.14$ & 39 & 46 & 15 & 33 & 45 & 23 \\
\hline Fatigue & 64 & 20 & $5.13 \pm 2.39$ & 32 & 42 & 26 & 22 & 63 & 16 \\
\hline Imbalance & 55 & 19 & $5.52 \pm 2.55$ & 38 & 33 & 29 & 18 & 61 & 21 \\
\hline Memory Loss & 23 & 4 & $4.05 \pm 2.64$ & 42 & 37 & 21 & 16 & 68 & 16 \\
\hline Vision Loss & 19 & 5 & $3.75 \pm 2.86$ & 53 & 33 & 13 & 27 & 67 & 7 \\
\hline Shortness of Breath & 29 & 6 & $3.88 \pm 2.38$ & 30 & 48 & 22 & 13 & 74 & 13 \\
\hline \multicolumn{10}{|c|}{$\begin{array}{l}{ }^{*} \text { All symptoms rated on } 0 \text { (none) to } 10 \text { (very severe) scale. } \\
{ }^{\dagger} \text { For those who endorsed symptom (i.e., rated symptom as } \geq 1 \text { ). For example, } 60 \text { participants ( } 72 \% \text { of entire sample) endorsed presence of pain. In column "Course } \\
\text { Since Onset," } 37 \% \text { of participants who endorsed pain indicated that their pain had gotten worse since onset. In other words, } 22 \text { participants ( } 37 \% \text { of } 60 \text { who } \\
\text { endorsed pain) reported their pain course since onset as worse. } \\
\text { SD = standard deviation. }\end{array}$} \\
\hline
\end{tabular}

more symptoms were reported to have gotten worse (range $=13 \%-33 \%)$ than improved (7\%-24\%), although this was not true for all symptoms (Table 1). In summary, study participants perceived that their symptoms have largely stayed the same over time, both during the past 6 months and since their onset. When the severity of their symptoms has changed, it is most often perceived as being in the direction of increased severity rather than decreased severity over time.

\section{Associations Among Symptom Severity Ratings}

The strongest correlations emerged between fatigue and shortness of breath $(r=0.52)$, fatigue and weakness $(r=0.46)$, fatigue and pain $(r=0.40)$, pain and weakness $(r=0.40)$, weakness and imbalance $(r=0.40)$, and weakness and memory loss $(r=0.40)$. As can be seen from Table 2, there were 13 associations with correlation coefficients ranging from 0.20 to 0.39 ; the remainder had coefficients below 0.20. In summary, the symptom severity ratings demonstrated relatively little statistical overlap. In fact, the two variables (fatigue and shortness of breath) that demonstrated the strongest association shared only 27 percent of their variances.

\section{Associations Between Symptoms and Functioning}

Table 3 contains the results of analyses examining the zero-order associations between the symptom severity ratings and the four measures of participant functioning. The overall pattern of results indicated that the participants' symptoms were more closely related to social inte- gration than they were to home integration, productive activity, and psychological functioning. The strongest associations were between social integration and the symptoms of vision loss ( $r=-0.33)$, memory loss ( $r=$ $-0.32)$, and weakness $(r=-0.23)$ and between psychological functioning and vision loss $(r=-0.24)$. These coefficients were negative, which indicated that greater symptom severity was related to poorer functioning. The five other symptoms demonstrated much weaker associations with the functioning domains, and none was statistically significant.

Although weak and/or nonsignificant correlations could result from range restriction in the functioning scores and/or symptom severity ratings, this does not appear to have been the reason for the current results. The CIQ subscales had a sufficiently wide range of scores (Home Integration: 0-10, Social Integration: 3-12, Productive Activity: $0-7$ ), and the symptom severity ratings ranged from 0 to 10 for five of the symptoms and 0 to 9 for the remaining three symptoms.

Consistent with the results of the zero-order correlation analyses, the symptom severity ratings were not significant predictors of the CIQ Home Integration or Productive Activity scales in the multiple regression analyses. In addition, the symptom ratings did not contribute significantly to the prediction of the SF-36 MHS. In contrast, after controlling for age and sex, the eight symptoms were significantly associated with the CIQ Social Integration scale (Table 4). As a group, these variables accounted for an additional 29 percent of the variance in social 
Table 2.

Correlation coefficients among symptom severity ratings.

\begin{tabular}{|c|c|c|c|c|c|c|c|c|}
\hline Symptom & Pain & Weakness & Fatigue & Imbalance & Numbness & Memory Loss & Vision Loss & $\begin{array}{c}\text { Shortness of } \\
\text { Breath }\end{array}$ \\
\hline$\overline{\text { Pain }}$ & 1.00 & - & - & - & - & - & - & - \\
\hline Weakness & $0.40^{*}$ & 1.00 & - & - & - & - & - & - \\
\hline Fatigue & $0.40^{*}$ & $0.46^{*}$ & 1.00 & - & - & - & - & - \\
\hline Imbalance & $0.25^{\dagger}$ & $0.40^{*}$ & $0.36^{\ddagger}$ & 1.00 & - & - & - & - \\
\hline Numbness & $0.30^{\ddagger}$ & 0.18 & 0.22 & 0.21 & 1.00 & - & - & - \\
\hline Vision Loss & 0.02 & $0.32^{\ddagger}$ & $0.31^{\ddagger}$ & 0.19 & 0.20 & $0.34^{\ddagger}$ & 1.00 & - \\
\hline Shortness of Breath & 0.07 & $0.28^{\dagger}$ & $0.52^{*}$ & 0.10 & 0.14 & 0.19 & $0.31^{\ddagger}$ & 1.00 \\
\hline $\begin{array}{l}{ }^{*} p<0.001 \\
{ }^{+} p<0.05 \\
{ }^{*} p<0.01\end{array}$ & & & & & & & & \\
\hline
\end{tabular}

Table 3.

Correlation coefficients between symptoms and functioning.

\begin{tabular}{lcccc}
\hline \multirow{1}{*}{ Symptom } & \multicolumn{1}{c}{ CIQ } & & SF-36 \\
\cline { 2 - 4 } \cline { 2 - 4 } & Home Integration & Social Integration & Productive Activity & Psychological Functioning \\
\hline Pain & 0.07 & 0.06 & -0.03 & 0.10 \\
Weakness & 0.10 & $-0.23^{*}$ & -0.04 & 0.02 \\
Fatigue & 0.00 & -0.08 & -0.04 & -0.09 \\
Imbalance & 0.02 & -0.10 & 0.04 & -0.10 \\
Numbness & 0.06 & -0.09 & -0.06 & -0.13 \\
Memory Loss & -0.19 & $-0.32^{\dagger}$ & -0.06 & $-0.24^{*}$ \\
Vision Loss & -0.21 & $-0.33^{\dagger}$ & -0.14 & -0.13 \\
Shortness of Breath & -0.08 & -0.17 & -0.11 & \\
${ }^{*} p<0.05$. & & & \\
${ }^{\dagger} p<0.01$. & & & \\
CIQ $=$ Community Integration Questionnaire, SF-36= Medical Outcomes Study 36-Item Short Form Health Survey. & \\
\hline \hline
\end{tabular}

Table 4.

Multiple regression analysis predicting Community Integration Questionnaire Social Integration from symptom severity ratings.

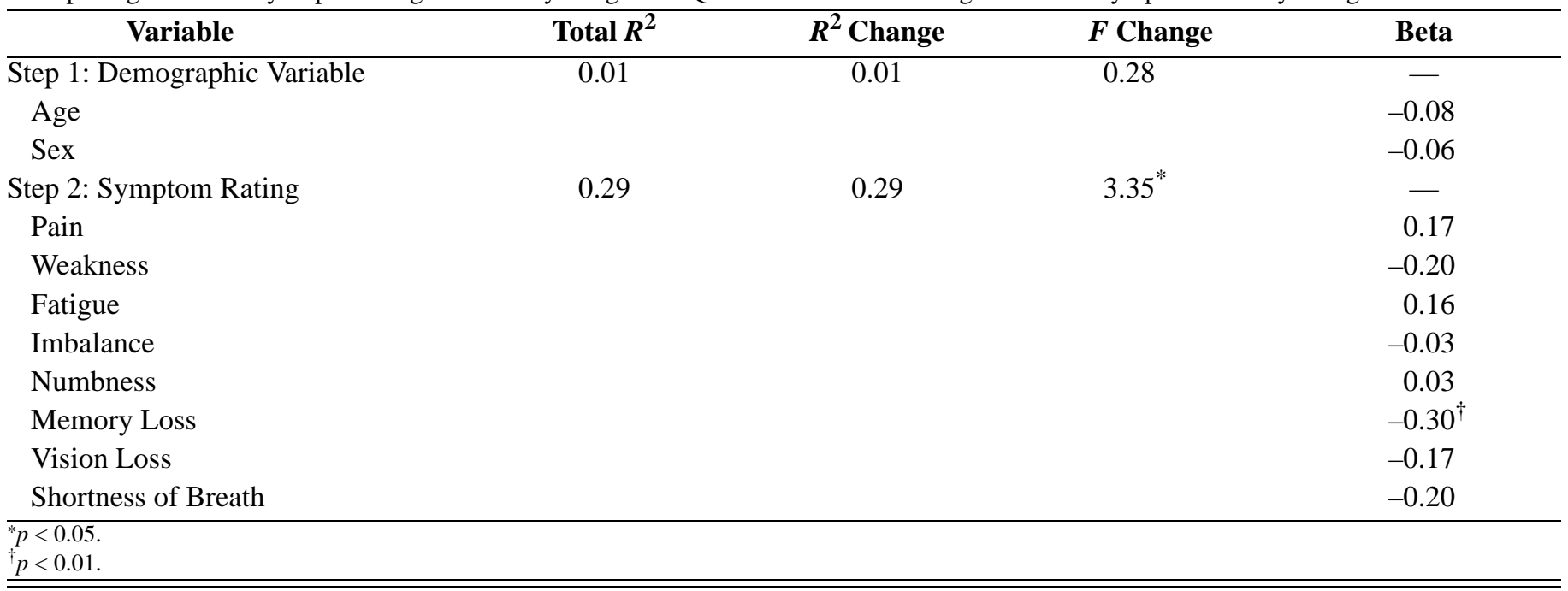


integration. Examination of the individual regression coefficients indicated that memory loss $(r=-0.30, p<0.05)$ was the only variable that made a unique and statistically significant contribution to the model.

\section{DISCUSSION}

The current study examined the frequency, severity, and course of a number of symptoms reported by adults with CP and their association with psychosocial functioning. Pain, fatigue, imbalance, and weakness emerged as the most common and most severe symptoms reported in this sample. All eight symptoms under study were more often reported to have either stayed the same or worsened than to have improved or resolved over time. Moreover, the symptoms - memory loss in particular-were more closely related to social integration than to other domains of community integration and psychological functioning. The results of this study provide new information about the experience of adults living with $\mathrm{CP}$ and have important implications for the assessment and treatment of symptoms in these patients.

As hypothesized, and consistent with previous reports [9-11], almost three-quarters of participants in this study reported the presence of pain. These findings highlight the need for ongoing pain assessment in adults with CP. Previous research and our own clinical experience indicate that these patients are at risk for having their pain inadequately assessed; this may be due to factors such as patient communication and cognitive difficulties [44], as well as provider biases and knowledge deficits [45]. It is important that pain assessment in adults with CP be tailored to the individual patient. For example, a standard numeric rating scale or visual analog scale may be appropriate for relatively high functioning individuals, whereas a scale depicting facial expressions (e.g., Faces Pain Scale [46]) may be preferred for those with cognitive impairments. A significant-other rating scale may be necessary for patients who lack the capacity to provide such selfreport information, although observation or significant other ratings should not replace patient self-report when patients are able to describe their experience [47].

In addition to its prevalence, both the severity and refractory nature of pain in the current sample was notable. These findings are consistent with the few previous studies that examined pain in adults with CP. Jensen et al. found relatively similar rates of moderate-to-severe pain in a sample of 50 adults with CP who were followed over a 2-year period [48]. Interestingly, despite using many different types of pain treatments (e.g., over-the-counter and prescription medication, physical activity/exercise, application of heat and ice) over the course of the study and the fact that these treatments were rated as providing at least a moderate amount of pain relief, the average pain intensity reported by the participants in this study was largely unchanged over time [48]. Engel et al. also investigated pain-related healthcare utilization in this population and found that a variety of pain treatments and healthcare providers were sought and used by study participants [35]. Moreover, although many of the interventions were rated as being helpful, only a small subset of the sample reportedly accessed these services [35]. Taken together, this emerging body of research points to a critical need for the development and provision of more effective treatments for pain in adults with CP.

The specific frequency and course of the other seven symptoms that were assessed in this study have received relatively little empirical attention to date. This is a conspicuous gap in the literature as indicated by the current findings; many of these symptoms were quite prevalent, severe, and refractory in nature. Specifically, more than half the sample reported fatigue, imbalance, and/or weakness, all of which were noted to have stayed the same or gotten worse over time. While it might be tempting to view these three symptoms as largely interchangeableindeed, few investigations have considered them independently - we believe this would be unwise for several reasons. As a matter of measurement, these symptoms shared, at most, only 21 percent of their variances, suggesting that the study participants did in fact consider these symptoms to be distinct from one another. Moreover, a given patient could certainly experience balance problems-perhaps as a consequence of vestibular dysfunction [49] — while still maintaining a normal level of strength and energy. Thus, although it is possible that fatigue, imbalance, and weakness are experienced concurrently by many individuals with $\mathrm{CP}$, it is important that both clinicians and researchers assess the presence and severity of the three symptoms separately.

Previous research has found fatigue and weakness to be common in individuals with CP and related to various indices of physical and psychological functioning [13$15,19]$. Weakness, in particular, was significantly associated with social functioning in the current sample, which is not surprising, since one would expect that individuals 
experiencing weakness would find it especially challenging to engage in social activities, particularly those that occur outside the home. Given the many positive physical and emotional benefits associated with satisfying social relations [50-53], providers may want to pay specific attention to the management of weakness in their patients with CP. Research has shown that interventions aimed at reducing weakness in this patient group can be quite effective [54].

Research on balance problems among individuals with CP has typically focused on children (e.g., Burtner et al. [55]) rather than adults. The current study, however, suggests that such problems are quite prevalent and severe in adults with CP. A recent longitudinal study by Scandinavian investigators also highlighted the importance of balance integrity in this population [56]. In that study, 149 adults with CP were followed over 7 years to determine changes in walking function. The results indicated that changes in balance were the most frequently reported determinants of changes in walking ability over time [56]. Additional research is needed that examines the causes and consequences of postural control and balance in adults with CP, as well as potential therapeutic strategies to improve any deficits. However, at this point, it does appear that these issues are prevalent and important enough to receive early and ongoing attention in the clinical setting.

The symptoms that were reported less frequently by this sample-numbness, shortness of breath, memory loss, and vision loss - have not been widely investigated in adults with CP. Nevertheless, these symptoms were endorsed by between one-fifth and one-third of participants, suggesting that they are experienced by a notinsignificant proportion of this patient population. Where prevalence estimates are available-specifically in the domains of memory [34] and visual [27] impairmentsthe current findings are generally consistent with previously observed rates. Moreover, much like the more prevalent symptoms that were assessed in this study, these less common symptoms were reported to have either stayed the same or worsened over time. The refractory nature of these symptoms may simply reflect the functional deficits that are characteristic of CP; however, it may also be the result of clinical inattention and/or ineffective treatment. Since memory and visual impairments demonstrated the closest associations to the functioning measures, it will be important for future research to further elucidate the prevalence, consequences, and most effective treatments for these symptoms, even if they do occur less frequently than other symptoms.

It was somewhat surprising that the individual symptom severity ratings were not more closely related to the four indices of psychosocial functioning. In fact, as a group, these variables only accounted for a significant amount of variance in the Social Integration scale of the CIQ, with memory loss being the only independent contributor in the prediction model. Even at the univariate level, the only significant associations were between social integration and vision loss, memory loss, and weakness and between psychological functioning and vision loss. It is difficult to contextualize these findings, given the relatively thin literature on the correlates of community integration and psychological functioning in adults with CP. A similar study by Jensen et al. in individuals with SCI also found that social integration was significantly associated with a group of seven symptoms (pain, fatigue, numbness, weakness, shortness of breath, vision loss, and memory loss) [42]. However, in that study, memory loss, weakness, pain, and vision loss were all unique predictors [42]. In addition, the group of symptoms was also significantly associated with psychological functioning in persons with SCI [42]. Although strong conclusions related to the current study are premature at this point for adults with CP, other symptoms that were not assessed in this study may be more important determinants of community integration and psychological functioning. In particular, psychological symptoms, which were not targeted in this study, may be particularly important in this context. For example, previous research has found symptoms of depression and anxiety to be associated with functioning in other patient populations, such as SCI [57-58] and multiple sclerosis [59-61]. Future research is needed to determine whether this is also true for adults with CP. It is also possible that we did not assess the functional domains that are particularly sensitive to the eight symptoms that were examined and/or that the instruments used to assess community integration and psychological functioning did not adequately capture these constructs in the current sample. These are empirical questions that could be investigated in future work.

Several limitations of the current study should be considered. First, the number of secondary symptoms that was assessed represents only a subset of those that are experienced by individuals with CP. Although we believe, and the current results support, that the eight symptoms that were examined are important, future research should 
include additional symptoms (e.g., spasms, bladder/bowel dysfunction, insomnia, and weight problems) in order to examine their frequency, course, and relationship to important functional domains. Second, and relatedly, only two domains of functioning were assessed: community integration and psychological functioning. Important domains such as physical functioning, social role functioning, and participation were not measured in this study and should be considered for future research. Third, some or all of the eight symptoms that were assessed in this study are multidimensional and contain magnitude, spatial, quality, and/or temporal components. Participants in this study rated only the magnitude of these symptoms on a 0 to 10 scale, which did not permit evaluation of the nature and effect of the other symptom dimensions. A fourth limitation concerns the cross-sectional nature of the data, which does not allow for causal interpretations about the relationships between symptoms and functioning. Nor do these data allow for investigation of actual (as opposed to perceived) symptom change over time. Such longitudinal work will, among other things, help elucidate the association between advancing age and functioning in CP. In the current sample, age was not significantly associated with ratings of current severity or course for any of the eight symptoms (data not presented). Fifth, the different data collection strategies (in-person and postal) could have elicited different responses from participants. Although this procedural variability could have influenced the results in some way, systematic differences between the data collection strategies were not evident. Sixth, data were not collected on participants' use of lower-limb orthoses, which is likely to be relevant to some of the assessed symptoms (e.g., imbalance, weakness). Finally, characteristics of the study sample may limit the generalizability of the findings. The participants were largely white, well-educated, and living independently, and almost half had spastic-type CP. Many of the participants had also been involved in previous research by our group, which could bias the current results. Moreover, although the response rate for the current study is standard for this type of research, it nevertheless represents only a subset of the population.

\section{CONCLUSIONS}

Despite the study limitations, the findings provide important information regarding the (high) rates of pain, fatigue, imbalance, and weakness in a sample of adults with CP. These symptoms - as well as those that were less prevalent-were perceived to be relatively refractory in nature and were most closely related to social integration. Future research is needed to replicate these findings in other samples of adults with CP and identify the primary correlates of psychosocial functioning in this patient population. Additional work is also needed to develop more effective treatments for the symptoms that are considered most problematic by these patients. Such research has the potential to improve the quality of life in adults living with CP.

\section{ACKNOWLEDGMENTS}

\section{Author Contributions:}

Study concept and design: A. T. Hirsh, J. C. Gallegos, K. J. Gertz, J. M. Engel, M. P. Jensen.

Data collection and analysis: A. T. Hirsh, J. C. Gallegos, K. J. Gertz, J. M. Engel, M. P. Jensen.

Manuscript preparation: A. T. Hirsh, J. C. Gallegos, K. J. Gertz, J. M. Engel, M. P. Jensen.

Financial Disclosures: The authors have declared that no competing interests exist.

Funding/Support: This material was based on work supported, in part, by the National Institutes of Health, National Institute of Child Health and Human Development, National Center for Medical Rehabilitation Research (grants T32 HD007424 and PO1 HD33988).

Additional Contributions: Portions of this research were published in abstract form subsequent to a poster presentation at the 31st Annual Meeting and Scientific Sessions of the Society of Behavioral Medicine (Hirsh AT, Gallegos JC, Gertz RJ, Engel JM, Jensen MP. Symptom burden in adults with cerebral palsy. Annals Behav Med. 2010;39:95). We acknowledge Amy Hoffman, Natalie Brown, Joseph Skala, Emily Phelps, Laura Nishimura, Lindsay Washington, Tyler Einheuser, Silvia Amtmann, and Eric Weitz for their assistance in data collection and management. Dr. Hirsh is now with the Indiana UniversityPurdue University at Indianapolis, Indiana.

Institutional Review: Informed consent was obtained from all participants in person prior to completing the questionnaire. All participants received a copy of the consent form for their records. All study procedures were approved by the institutional review board at the University of Washington.

Participant Follow-Up: The authors do not plan to inform participants of the publication of this study.

\section{REFERENCES}

1. Bax M, Goldstein M, Rosenbaum P, Leviton A, Paneth N, Dan B, Jacobsson B, Damiano D; Executive Committee for the Definition of Cerebral Palsy. Proposed definition and 
classification of cerebral palsy, April 2005. Dev Med Child Neurol. 2005;47(8):571-76. [PMID: 16108461]

DOI:10.1017/S001216220500112X

2. Ando N, Ueda S. Functional deterioration in adults with cerebral palsy. Clin Rehabil. 2000;14(3):300-306.

[PMID: 10868725]

DOI:10.1191/026921500672826716

3. Gajdosik CG, Cicirello N. Secondary conditions of the musculoskeletal system in adolescents and adults with cerebral palsy. Phys Occup Ther Pediatr. 2001;21(4):49-68. [PMID: 12043172]

4. Murphy KP, Molnar GE, Lankasky K. Medical and functional status of adults with cerebral palsy. Dev Med Child Neurol. 1995;37(12):1075-84. [PMID: 8566465] DOI:10.1111/j.1469-8749.1995.tb11968.x

5. Overeynder JC, Turk MA. Cerebral palsy and aging: A framework for promoting the health of older persons with cerebral palsy. Top Geriatr Rehabil. 1998;13(3):19-24.

6. Crichton JU, Mackinnon M, White CP. The life-expectancy of persons with cerebral palsy. Dev Med Child Neurol. 1995; 37(7):567-76. [PMID: 7615144]

7. Evans PM, Evans SJ, Alberman E. Cerebral palsy: Why we must plan for survival. Arch Dis Child. 1990;65(12):1329-33. [PMID: 2148667]

DOI:10.1136/adc.65.12.1329

8. McDonald EP. Medical needs of severely developmentally disabled persons residing in the community. Am J Ment Defic. 1985;90(2):171-76. [PMID: 2931984$]$

9. Turk MA, Geremski CA, Rosenbaum PF, Weber RJ. The health status of women with cerebral palsy. Arch Phys Med Rehabil. 1997;78(12 Suppl 5):S10-S17. [PMID: 9422002] DOI:10.1016/S0003-9993(97)90216-1

10. Schwartz L, Engel JM, Jensen MP. Pain in persons with cerebral palsy. Arch Phys Med Rehabil. 1999;80(10): 1243-46. [PMID: 10527081] DOI:10.1016/S0003-9993(99)90023-0

11. Engel JM, Jensen MP, Hoffman AJ, Kartin D. Pain in persons with cerebral palsy: Extension and cross validation. Arch Phys Med Rehabil. 2003;84(8):1125-28. [PMID: 12917849$]$ DOI:10.1016/S0003-9993(03)00263-6

12. Jahnsen R, Villien L, Egeland T, Stanghelle JK, Holm I. Locomotion skills in adults with cerebral palsy. Clin Rehabil. 2004;18(3):309-16. [PMID: 15137562]

DOI:10.1191/0269215504cr7350a

13. Jahnsen R, Villien L, Stanghelle JK, Holm I. Fatigue in adults with cerebral palsy in Norway compared with the general population. Dev Med Child Neurol. 2003;45(5): 296-303. [PMID: 12729142] DOI:10.1111/j.1469-8749.2003.tb00399.x

14. Klingbeil H, Baer HR, Wilson PE. Aging with a disability. Arch Phys Med Rehabil. 2004;85(7 Suppl 3):S68-S73.

\section{[PMID: 15221734]}

DOI:10.1016/j.apmr.2004.03.014

15. Leonard CT, Moritani T, Hirschfeld H, Forssberg H. Deficits in reciprocal inhibition of children with cerebral palsy as revealed by $\mathrm{H}$ reflex testing. Dev Med Child Neurol. 1990;32(11):974-84. [PMID: 2269407] DOI:10.1111/j.1469-8749.1990.tb08120.x

16. Dietz V, Berger W. Cerebral palsy and muscle transformation. Dev Med Child Neurol. 1995;37(2):180-84.

[PMID: 7851674] DOI:10.1111/j.1469-8749.1995.tb11987.x

17. Myklebust BM, Gottlieb GL, Penn RD, Agarwal GC. Reciprocal excitation of antagonistic muscles as a differentiating feature in spasticity. Ann Neurol. 1982;12(4):367-74. [PMID: 7149662]

DOI:10.1002/ana.410120409

18. Damiano DL, Quinlivan J, Owen BF, Shaffrey M, Abel MF. Spasticity versus strength in cerebral palsy: Relationships among involuntary resistance, voluntary torque, and motor function. Eur J Neurol. 2001;8(Suppl 5):40-49.

[PMID: 11851733]

DOI:10.1046/j.1468-1331.2001.00037.x

19. Van den Berg-Emons RJ, Van Baak MA, De Barbanson DC, Speth L, Saris WH. Reliability of tests to determine peak aerobic power, anaerobic power and isokinetic muscle strength in children with spastic cerebral palsy. Dev Med Child Neurol. 1996;38(12):1117-25. [PMID: 8973297] DOI:10.1111/j.1469-8749.1996.tb15075.x

20. Koumbourlis AC. Scoliosis and the respiratory system. Paediatr Respir Rev. 2006;7(2):152-60. [PMID: 16765303] DOI:10.1016/j.prrv.2006.04.009

21. Majd ME, Muldowny DS, Holt RT. Natural history of scoliosis in the institutionalized adult cerebral palsy population. Spine. 1997;22(13):1461-66. [PMID: 9231964] DOI:10.1097/00007632-199707010-00007

22. Rochester DF, Esau SA. Assessment of ventilatory function in patients with neuromuscular disease. Clin Chest Med. 1994;15(4):751-63. [PMID: 7867289]

23. Grandas NF, Jain NB, Denckla JB, Brown R, Tun CG, Gallagher ME, Garchich E. Dyspnea during daily activities in chronic spinal cord injury. Arch Phys Med Rehabil. 2005; 86(8):1631-35. [PMID: 16084818]

DOI:10.1016/j.apmr.2005.02.006

24. Spungen AM, Grimm DR, Schilero G, Lenner R, Oei E, Bauman WA, Almenoff PL, Lesser M. Relationship of respiratory symptoms with smoking status and pulmonary function in chronic spinal cord injury. J Spinal Cord Med. 2002;25(1):23-27. [PMID: 11939462]

25. Andersson C, Mattsson E. Adults with cerebral palsy: A survey describing problems, needs, and resources, with special emphasis on locomotion. Dev Med Child Neurol. 2001; 
43(2):76-82. [PMID: 11221908]

DOI:10.1017/S0012162201

26. Nwaobi OM, Smith PD. Effect of adaptive seating on pulmonary function of children with cerebral palsy. Dev Med Child Neurol. 1986;28(3):351-54. [PMID: 3721078]

DOI:10.1111/j.1469-8749.1986.tb03883.x

27. Brown MC, Bontempo A, Turk MA. Secondary consequences of cerebral palsy: Adults with cerebral palsy in New York state. Albany (NY): Developmental Disabilities Planning Council; 1992.

28. Janicki MP. Aging, cerebral palsy, and older persons with mental retardation. J Intellect Dev Disabil. 1989;15(3-4): 311-20. DOI:10.1080/07263868900033771

29. Schenker R, Coster WJ, Parush S. Neuroimpairments, activity performance, and participation in children with cerebral palsy mainstreamed in elementary schools. Dev Med Child Neurol. 2005;47(12):808-14. [PMID: 16288670]

DOI:10.1017/S0012162205001714

30. Bolla KI, Lindgren KN, Bonaccorsy C, Bleecker ML. Memory complaints in older adults: Fact or fiction? Arch Neurol. 1991;48(1):61-64. [PMID: 1986728]

31. Cutler SJ, Grams AE. Correlates of self-reported everyday memory problems. J Gerontol. 1988;43(3):S82-S90. [PMID: 3361099]

32. Ponds RW, Van Boxtel MP, Jolles J. Age-related changes in subjective cognitive functioning. Educ Gerontol. 2000;26(1): 67-81. DOI:10.1080/036012700267402

33. Small SA. Age-related memory decline: Current concepts and future directions. Arch Neurol. 2001;58(3):360-64. [PMID: 11255438]

DOI:10.1001/archneur.58.3.360

34. Pueyo R, Junqué C, Vendrell P, Narberhaus A, Segarra D. Neuropsychologic impairment in bilateral cerebral palsy. Pediatr Neurol. 2009;40(1):19-26. [PMID: 19068249] DOI:10.1016/j.pediatrneurol.2008.08.003

35. Engel JM, Kartin D, Jensen MP. Pain treatment in persons with cerebral palsy: Frequency and helpfulness. Am J Phys Med Rehabil. 2002;81(4):291-96. [PMID: 11953547] DOI:10.1097/00002060-200204000-00009

36. Folstein MF, Folstein SE, McHugh PR. "Mini-mental state.” A practical method for grading the cognitive state of patients for the clinician. J Psychiatr Res. 1975;12(3):189-98. [PMID: 1202204] DOI:10.1016/0022-3956(75)90026-6

37. Sander AM, Fuchs KL, High WM Jr, Hall KM, Kreutzer JS, Rosenthal M. The Community Integration Questionnaire revisited: An assessment of factor structure and validity. Arch Phys Med Rehabil. 1999;80(10):1303-8.

[PMID: 10527092]

DOI:10.1016/S0003-9993(99)90034-5

Erratum in: Arch Phys Med Rehabil. 1999;80(12):1608.
38. Willer B, Rosenthal M, Kreutzer JS, Gordon WA, Rempel R. Assessment of community integration following rehabilitation for traumatic brain injury. J Head Trauma Rehabil. 1993;8(2):75-87.

DOI:10.1097/00001199-199308020-00009

39. Ware JE, Snow KK, Kosinski M. SF-36 Health Survey: Manual and interpretation guide. Lincoln (RI): Quality Metric Inc; 2000.

40. Dijkers M. Quality of life after spinal cord injury: A meta analysis of the effects of disablement components. Spinal Cord. 1997;35(12):829-40. [PMID: 9429262]

DOI:10.1038/sj.sc.3100571

41. Fleming J, Tooth L, Hassell M, Chan W. Prediction of community integration and vocational outcome $2-5$ years after traumatic brain injury rehabilitation in Australia. Brain Inj. 1999;13(6):417-31. [PMID: 10401543]

DOI:10.1080/026990599121476

42. Jensen MP, Kuehn CM, Amtmann D, Cardenas DD. Symptom burden in persons with spinal cord injury. Arch Phys Med Rehabil. 2007;88(5):638-45. [PMID: 17466734] DOI:10.1016/j.apmr.2007.02.002

43. Kaplan CP. The Community Integration Questionnaire with new scoring guidelines: Concurrent validity and need for appropriate norms. Brain Inj. 2001;15(8):725-31.

[PMID: 11485612] DOI:10.1080/02699050010005913

44. Oberlander TF, O’Donnell ME, Montgomery CJ. Pain in children with significant neurological impairment. J Dev Behav Pediatr. 1999;20(4):235-43. [PMID: 10475598] DOI:10.1097/00004703-199908000-00005

45. Murphy KP. Medical problems in adults with cerebral palsy: Case examples. Assist Technol. 1999;11(2):97-104. [PMID: 11010070]

46. Bieri D, Reeve RA, Champion GD, Addicoat L, Ziegler JB. The Faces Pain Scale for the self-assessment of the severity of pain experienced by children: Development, initial validation, and preliminary investigation for ratio scale properties. Pain. 1990;41(2):139-50. [PMID: 2367140$]$

47. Herr K, Coyne PJ, Key T, Manworren R, McCaffery M, Merkel S, Pelosi-Kelly J, Wild L; American Society for Pain Management Nursing. Pain assessment in the nonverbal patient: Position statement with clinical practice recommendations. Pain Manag Nurs. 2006;7(2):44-52. [PMID: 16730317] DOI:10.1016/j.pmn.2006.02.003

48. Jensen MP, Engel JM, Hoffman AJ, Schwartz L. Natural history of chronic pain and pain treatment in adults with cerebral palsy. Am J Phys Med Rehabil. 2004;83(6):439-45. [PMID: 15166688] DOI:10.1097/00002060-200406000-00006

49. Angelaki DE, Cullen KE. Vestibular system: The many facets of a multimodal sense. Annu Rev Neurosci. 2008;31: 
125-50. [PMID: 18338968]

DOI:10.1146/annurev.neuro.31.060407.125555

50. Everard KM, Lach HW, Fisher EB, Baum MC. Relationship of activity and social support to the functional health of older adults. J Gerontol B Psychol Sci Soc Sci. 2000; 55(4):S208-12. [PMID: 11584883]

51. Fabrigoule C, Letenneur L, Dartigues JF, Zarrouk M, Commenges D, Barberger-Gateau P. Social and leisure activities and risk of dementia: A prospective longitudinal study. J Am Geriatr Soc. 1995;43(5):485-90. [PMID: 7730528]

52. Glass TA, De Leon CM, Marottoli RA, Berkman LF. Population based study of social and productive activities as predictors of survival among elderly Americans. BMJ. 1999; 319(7208):478-83. [PMID: 10454399]

53. Seeman TE. Social ties and health: The benefits of social integration. Ann Epidemiol. 1996;6(5):442-51. [PMID: 8915476$]$ DOI:10.1016/S1047-2797(96)00095-6

54. Givon U. [Muscle weakness in cerebral palsy.] Acta Orthop Traumatol Turc. 2009;43(2):87-93. Turkish.

[PMID: 19448347] DOI:10.3944/AOTT.2009.087

55. Burtner PA, Woollacott MH, Craft GL, Roncesvalles MN. The capacity to adapt to changing balance threats: A comparison of children with cerebral palsy and typically developing children. Dev Neurorehabil. 2007;10(3):249-60. [PMID: 17564865] DOI:10.1080/17518420701303066

56. Opheim A, Jahnsen R, Olsson E, Stanghelle JK. Walking function, pain, and fatigue in adults with cerebral palsy: A 7-year follow-up study. Dev Med Child Neurol. 2009; 51(5):381-88. [PMID: 19207296] DOI:10.1111/j.1469-8749.2008.03250.x

57. Nicholson Perry K, Nicholas MK, Middleton J. Spinal cord injury-related pain in rehabilitation: A cross-sectional study of relationships with cognitions, mood and physical function. Eur J Pain. 2009;13(5):511-17. [PMID: 18653364] DOI:10.1016/j.ejpain.2008.06.003
58. Tawashy AE, Eng JJ, Lin KH, Tang PF, Hung C. Physical activity is related to lower levels of pain, fatigue and depression in individuals with spinal-cord injury: A correlational study. Spinal Cord. 2009;47(4):301-6. [PMID: 18936771] DOI:10.1038/sc.2008.120

59. McIvor GP, Riklan M, Reznikoff M. Depression in multiple sclerosis as a function of length and severity of illness, age, remissions, and perceived social support. J Clin Psychol. 1984;40(4):1028-33. [PMID: 6480837] DOI:10.1002/1097-4679(198407)40:4<1028::AIDJCLP2270400427>3.0.CO;2-1

60. Mohr DC, Dick LP, Russo D, Pinn J, Boudewyn AC, Likosky W, Goodkin DE. The psychosocial impact of multiple sclerosis: Exploring the patient's perspective. Health Psychol. 1999;18(4):376-82. [PMID: 10431939]

DOI:10.1037/0278-6133.18.4.376

61. Drulovic J, Pekmezovic T, Matejic B, Mesaros S, Manigoda M, Dujmovic I, Stojsavljevic N, Kocev N, GavricKezic M, Nikic P, Dragojlovic M. Quality of life in patients with multiple sclerosis in Serbia. Acta Neurol Scand. 2007; 115(3):147-52. [PMID: 17295708] DOI:10.1111/j.1600-0404.2006.00729.x

Submitted for publication March 2, 2010. Accepted in revised form June 14, 2010.

This article and any supplementary material should be cited as follows:

Hirsh AT, Gallegos JC, Gertz KJ, Engel JM, Jensen MP. Symptom burden in individuals with cerebral palsy. J Rehabil Res Dev. 2010;47(9):863-76.

DOI:10.1682/JRRD.2010.03.0024

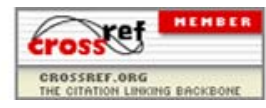


